\title{
New Ladle Exchanging Facilities for Continuous Caster*
}

\section{Introduction}

Plant and Machinery Division of Nippon Steel Corporation has developed new facilities for exchanging ladle which can be installed in the existing plants such as electric furnaces.

The present facilities are intended to utilize the existing ladle crane and to secure a pass line on the ground floor.

\section{New Ladle Exchanging Method}

The new ladle exchanging facilities consist of ladle, crane, ladle lifter, and ladle turret as shown in Fig. 1.

The procedure of ladle exchange starts with placement of a new ladle by the crane on the frame of ladle lifter at its lowest position (Fig. 2). The ladle on the lifting frame is hoisted up as high as to be moved onto the turret arm.

The ladle transferring device works in the following procedure. With start of hoisting of the lifting frame sustaining a ladle, support blocks above the lifter are ready to hold the ladle by swinging into the frame when it reaches up to the highest position. After the ladle is kept on the support blocks, the ladle lifter is brought down. By use of this ladle transferring device, the ladle can be lifted beyond the limit of crane elevation in the existing building.

The present method can contribute optimization of the layout for installation of a new continuous caster in the existing building. The advantages of the new facilities are saving of the investment for extra construction and selection of the layout for optimum installa- tion of a caster.

The facilities are successfully operating in Nakayama Steel with the following specification.

$\begin{array}{lll}\text { Ladle capacity } & : & 70 \mathrm{t} \\ \text { Ladle lifter } & & \\ \text { Lifting capacity } & : & 110 \mathrm{t} \\ \text { Lifting height } & : & 7.65 \mathrm{~m} \\ \text { Lifting speed } & : & 2.5 \mathrm{~m} / \mathrm{min} \\ \text { Ladle turret } & & \\ \text { Loading capacity: } & 110 \mathrm{t} \text { for } \\ & \text { each arm } \\ \text { Slewing radius } & : 5.5 \mathrm{~m} \\ \text { Slewing speed } & : & 1.0 \mathrm{rpm}\end{array}$

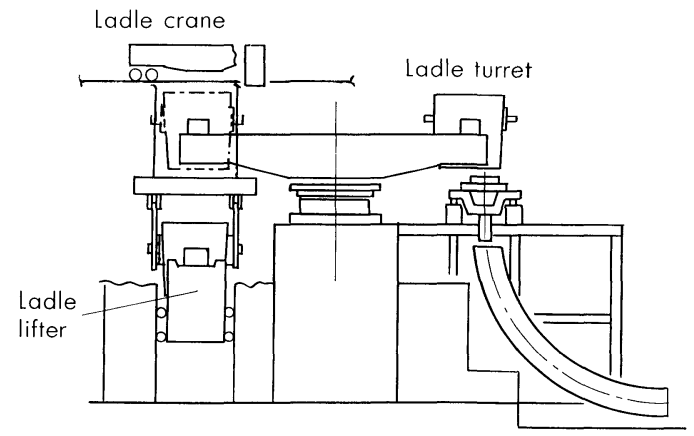

Fig. 1. New ladle-exchanging method.

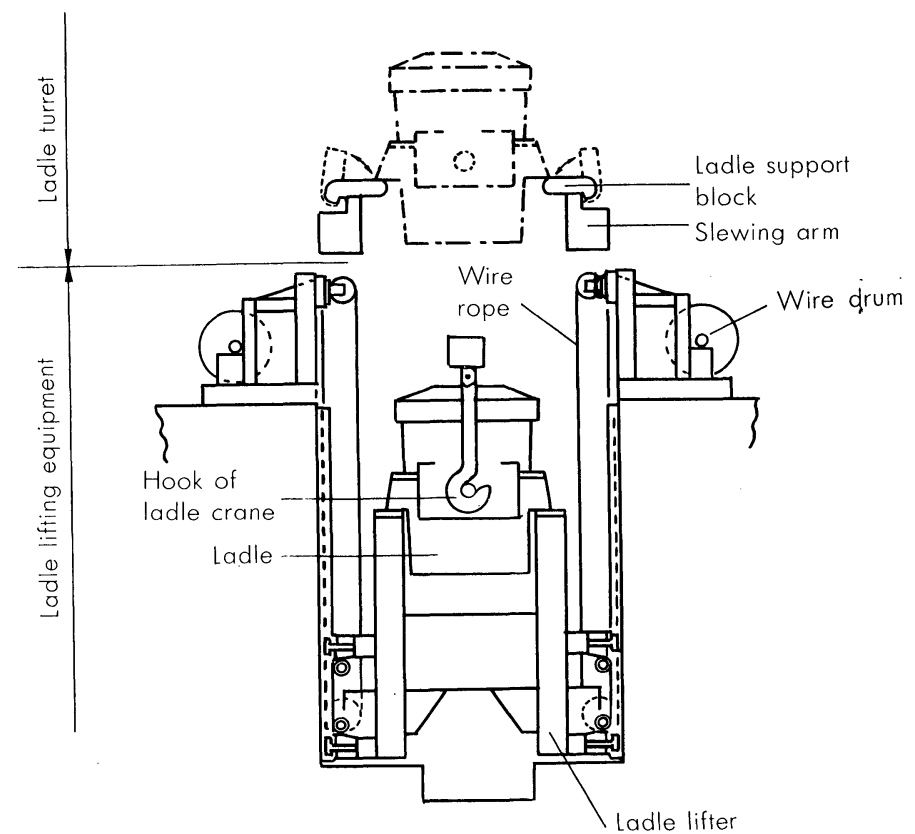

Fig. 2. Schematic illustration of ladle lifter.

\footnotetext{
* For further information, write to Plant \& Machinery Division, Nippon Steel Corporation, 46-59, Oaza Nakahara, Tobata-ku, Kitakyushu 804. (C) 1986 ISIJ
} 